\title{
Cumulus Microphysics and Climate Sensitivity
}

\author{
Anthony D. Del Genio \\ NASA Goddard Institute for Space Studies, New York, New York \\ WILLIAM Kovari \\ Center for Climate Systems Research, Columbia University, New York, New York \\ MaO-Sung YaO \\ SGT, Inc., Institute for Space Studies, New York, New York \\ JEFFREY JONAS \\ Center for Climate Systems Research, Columbia University, New York, New York
}

(Manuscript received 24 May 2004, in final form 15 October 2004)

\begin{abstract}
Precipitation processes in convective storms are potentially a major regulator of cloud feedback. An unresolved issue is how the partitioning of convective condensate between precipitation-size particles that fall out of updrafts and smaller particles that are detrained to form anvil clouds will change as the climate warms. Tropical Rainfall Measuring Mission (TRMM) observations of tropical oceanic convective storms indicate higher precipitation efficiency at warmer sea surface temperature (SST) but also suggest that cumulus anvil sizes, albedos, and ice water paths become insensitive to warming at high temperatures. International Satellite Cloud Climatology Project (ISCCP) data show that instantaneous cirrus and deep convective cloud fractions are positively correlated and increase with SST except at the highest temperatures, but are sensitive to variations in large-scale vertical velocity. A simple conceptual model based on a Marshall-Palmer drop size distribution, empirical terminal velocity-particle size relationships, and assumed cumulus updraft speeds reproduces the observed tendency for detrained condensate to approach a limiting value at high SST. These results suggest that the climatic behavior of observed tropical convective clouds is intermediate between the extremes required to support the thermostat and adaptive iris hypotheses.
\end{abstract}

\section{Introduction}

State-of-the-art general circulation models (GCMs) subjected to external climate forcings produce global net cloud feedbacks ranging from moderately negative to strongly positive, and individual shortwave (SW) and longwave (LW) cloud feedback components often differ in sign among models with similar net cloud feedback (Cess et al. 1996). This implies that different GCMs often predict different but compensating changes in the occurrence and properties of different

Corresponding author address: Anthony D. Del Genio, NASA Goddard Institute for Space Studies, 2880 Broadway, New York, NY 10025.

E-mail: adelgenio@giss.nasa.gov cloud types. This is possible because few observational constraints exist to ascertain the sign of specific cloud feedbacks.

A good example of this uncertainty is the role of convective systems in cloud and water vapor feedback. Deep convective clouds occupy a small area but are often accompanied by areally extensive anvils that dominate tropical planetary albedo and thinner cirrus clouds that modulate outgoing longwave radiation (OLR). Convective cirrus clouds and anvils form from detrainment of condensate formed in cumulus updrafts and from in situ mesoscale vertical motions within the anvils. Some anvil ice sublimes and along with detrained water vapor from the updraft provides a significant source of water vapor to the upper troposphere. The complexity of the dynamics and microphysics in 
convective updrafts makes it difficult to correctly characterize the water cycle of convective systems in numerical models, that is, the balance between the precipitation sink that reduces updraft condensate and the nonprecipitating condensate that represents the major source for the anvil cloud.

Two diametrically opposed ideas about the competition between precipitation and detrainment in a climate change have appeared in the literature. The thermostat hypothesis (Ramanathan and Collins 1991) suggests that in a warmer climate, increased boundary layer water vapor will increase condensation in convective clouds and thus increase detrainment, leading to more extensive and thicker anvils. Because the shortwave cloud forcing (SWCF) of tropical convective systems slightly exceeds their longwave cloud forcing (LWCF), this suggests a negative cloud feedback, although the additional water vapor source for the upper troposphere implies a positive water vapor feedback. The adaptive iris hypothesis (Lindzen et al. 2001) argues that increased precipitation efficiency because of increased convective condensate in a warmer climate will reduce detrainment, leading to a negative water vapor feedback and a slightly positive cloud feedback once the radiative properties of tropical clouds are properly accounted for (Lin et al. 2002).

Both analyses fail to account for vertical velocity effects, since warm sea surface temperatures (SSTs) are often accompanied by upward mean motion that promotes high cloud formation (cf. Fu et al. 1992; Hartmann and Michelsen 2002). Del Genio and Kovari (2002) analyzed the hydrological and radiative properties of tropical precipitating storms in Tropical Rainfall Measuring Mission (TRMM) data and separated them according to monthly mean SST and vertical velocity. They found that SW albedos and ice water paths of convective storms were insensitive to SST variations at warm temperatures. These results apply only to the precipitating area of the storms, however; the more extensive nonprecipitating areas of cirrus and cirrostratus were not explored.

Drawing inferences about cloud feedback in a forced climate change from such observed variability is risky. Current climate variability is typically driven at the airsea interface, and anomalies in vertical structure may be qualitatively different from those associated with forced climate changes, which are driven at the atmospheric emission level. For example, doubled $\mathrm{CO}_{2}$ experiments with the Goddard Institute for Space Studies (GISS) GCM predict stronger upper-level radiative cooling, mid- and upper-level convective heating, and boundary layer convective and radiative heating anomalies than do SST perturbation simulations, normalized by the column-integrated heating. Furthermore, natural and forced variability in general will have different horizontal patterns of change and thus different dynamical responses in several parameters that affect clouds. We therefore feel that the most prudent use of satellite data is to provide useful physical property and process constraints that can serve as the basis for the design and/or evaluation of global climate model parameterizations that are used to predict cloud feedback.

This paper extends the results of Del Genio and Kovari (2002) to all high cloud types and explores the implications of observed convective storm behavior for cloud feedback. Section 2 describes the data sources and analysis methods. Sections 3 and 4 explore the SST and vertical velocity dependences of TRMM storm properties and ISCCP high cloud types, respectively. Section 5 describes a simple conceptual model that captures the essentials of the TRMM-observed behavior and might serve as the basis for an improved parameterization of convective microphysics in GCMs. Implications of our work are discussed in section 6 .

\section{Data}

The analysis of TRMM data follows the procedure described fully in Del Genio and Kovari (2002). Instantaneous TRMM Microwave Imager (TMI) product 2A12 rain rates and hydrometeor profiles (Kummerow et al. 2001) for the period 1-5 February 1998 are used to define storms as contiguous raining areas with cloud water above the $5-\mathrm{km}$ level in the $\pm 15^{\circ}$ latitude band. Storm area-averaged rain rates and ice water paths (IWP) are calculated for each of 6765 storms detected over ocean. Coincident Clouds and the Earth's Radiant Energy System (CERES) data provide storm-averaged SW albedos and OLR. Del Genio and Kovari (2002) used the original CERES ES-8 [Earth Radiation Budget Experiment (ERBE)-like] products, but for this paper we have redone the analysis using the more accurate CERES Single Scanner Footprint (SSF) retrievals (Wielicki et al. 1996).

International Satellite Cloud Climatology Project (ISCCP) D1 retrievals (Rossow and Schiffer 1999) provide joint distributions of visible optical thickness $(\tau)$ and cloud-top pressure $(p)$ at $\sim 5 \mathrm{~km}$ resolution sampled to $30 \mathrm{~km}$ and aggregated over $2.5^{\circ} \times 2.5^{\circ}$ latitude-longitude areas. For this study we use the high cloud types $(p<440 \mathrm{mb}$ ) defined by ISCCP as follows: cirrus, $\mathrm{Ci}(\tau<3.6)$, cirrostratus, $\mathrm{Cs}(3.6<\tau<23)$, and deep convective clouds, DCC $(\tau>23)$. The Cs category generally includes the transition from precipitating to 

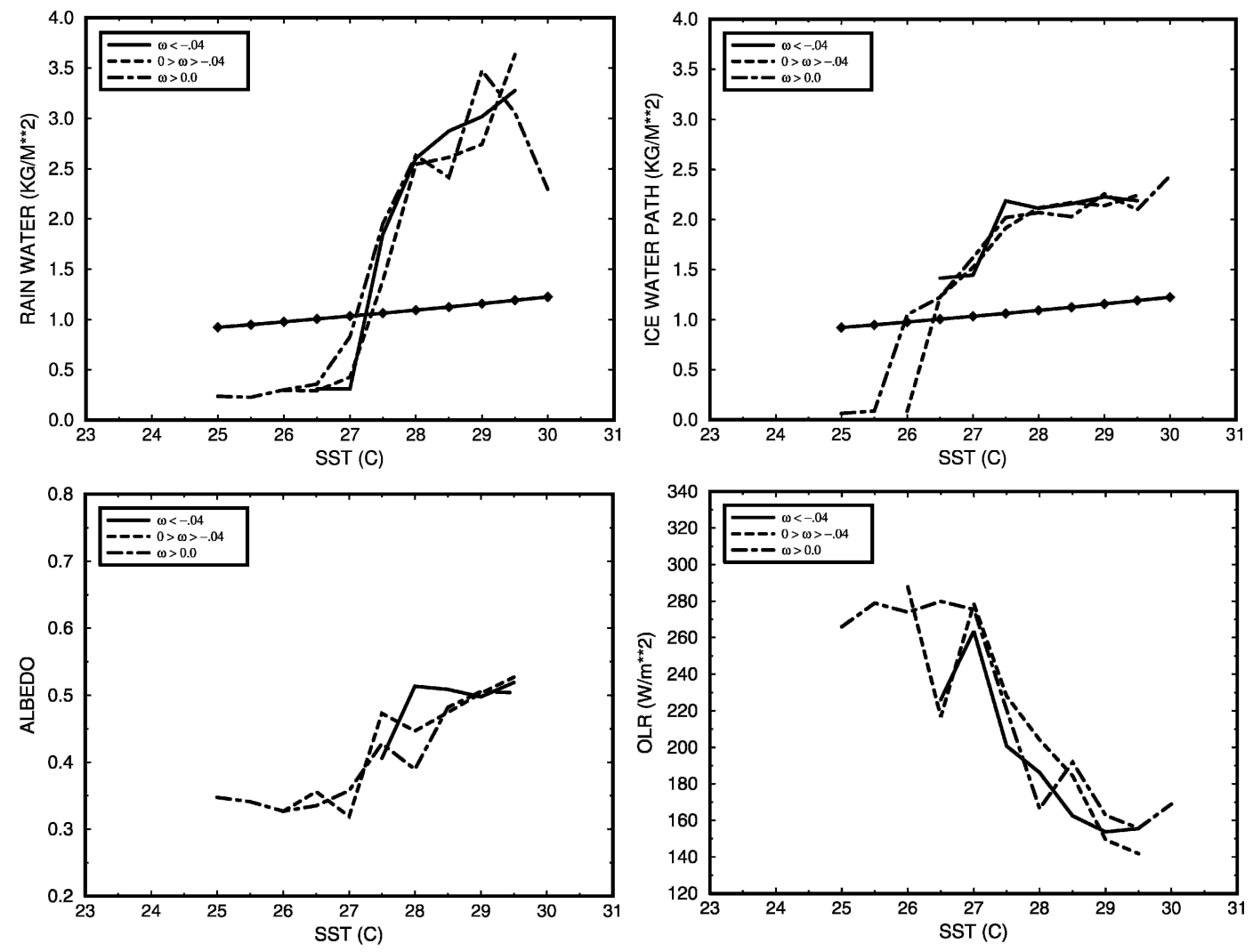

FIG. 1. (top left) Storm-averaged TMI rainwater path per hour, (top right) TMI ice water path, (bottom left) CERES albedo, and (bottom right) CERES OLR vs SST for three 500-mb $\omega$ ranges: $<-0.04 \mathrm{~Pa} \mathrm{~s}^{-1}$ (solid), -0.04 to $0 \mathrm{~Pa} \mathrm{~s}^{-1}$ (dashed), and $>0 \mathrm{~Pa} \mathrm{~s}^{-1}$ (dash-dot). (top) The solid line with diamonds shows the estimated boundary layer precipitable water vapor.

nonprecipitating portions of cumulus anvils, so TRMM raining areas are combinations of DCC and some Cs ISCCP pixels. Ci pixels represent the only high clouds with positive net cloud forcing in the ISCCP dataset.

Storm and high cloud property statistics are aggregated as functions of monthly mean sea surface temperature, obtained from the HadISST climatology (Rayner et al. 2003), and 500-mb vertical velocity $(\omega)$ averaged over the 5-day period of TRMM observations, obtained from the European Centre for MediumRange Weather Forecasting reanalysis (ERA-40; Simmons and Gibson 2000), at $2.5^{\circ} \times 2.5^{\circ}$ resolution. We explore the SST dependence in three vertical velocity categories: strong upwelling $\left(\omega<-0.04 \mathrm{~Pa} \mathrm{~s}^{-1}\right)$, weak upwelling $\left(0>\omega>-0.04 \mathrm{~Pa} \mathrm{~s}^{-1}\right)$, and downwelling ( $\omega$ $\left.>0 \mathrm{~Pa} \mathrm{~s}^{-1}\right)$. For this purpose, the properties of each TRMM storm are associated with the SST and $\omega$ for the $2.5^{\circ} \times 2.5^{\circ}$ box that includes the storm center location. For each $0.5^{\circ} \mathrm{C} \mathrm{SST}$ interval, the storm properties are binned into the three $\omega$ categories and then averaged over all storms in each category.

\section{Storm hydrological and radiative properties}

Figure 1 (upper left) shows TMI rainwater paths per hour of storm lifetime versus SST for each $\omega$ category, while Fig. 1 (upper right) shows mean storm IWP versus SST, an indirect measure of the amount of detrainment. Also shown in each figure is an estimate of the boundary layer water vapor available for condensation, assuming it to be well-mixed over a 500-m thick layer at a value consistent with $80 \%$ surface relative humidity. At constant relative humidity, boundary layer water vapor increases by $\sim 50 \%$ over the range of SST in this figure, according to the Clausius-Clapeyron equation. Rainwater path per hour of storm lifetime increases much more sharply with SST, especially at $27^{\circ}-28^{\circ} \mathrm{C}$, but at higher SST as well except in downwelling regions. The increase is otherwise independent of $\omega$. Thus, precipitation efficiency, defined here as the fraction of available boundary layer water vapor that is rained out, increases monotonically with warming, as the iris theory requires. On the other hand, IWP increases sharply initially with SST (as the thermostat 
hypothesis requires) but it asymptotes to a maximum value at the warmest temperatures, also with no noticeable $\omega$ dependence. Thus, detrainment efficiency, defined here as the fraction of boundary layer water vapor converted to anvil ice, slightly decreases with SST above a maximum at $27^{\circ}-28^{\circ} \mathrm{C}$, because IWP levels off while water vapor slowly but monotonically increases at the highest SSTs. This latter behavior is analogous to that described in the adaptive iris theory, but the more relevant feedback quantity is the absolute IWP, which levels off but does not decrease at all with SST. The observations thus paint a picture intermediate between the thermostat and iris extremes, that is, each hypothesis correctly characterizes one aspect of the convective water budget but not the other one.

The lower panels of Fig. 1 show CERES mean storm albedo (left) and OLR (right) in similar fashion. Albedo increases with SST and appears to level off at the highest SSTs. This behavior is similar to that of IWP, although the albedo increase from cold to warm SST is not as large. This may be due to contributions to the albedo from liquid water, which we will show later to be fairly insensitive to SST, and from particle size variations, which will offset the effect of IWP variations on albedo if larger particles accompany higher IWPs. The modest increase of albedo with SST is one difference between the CERES SSF and ES- 8 products; the latter showed no SST dependence except for the largest storms (Del Genio and Kovari 2002). OLR decreases with SST, especially above $27^{\circ} \mathrm{C}$, implying higher cloud tops and thicker clouds at warmer temperatures. This explains the SST dependence of IWP, since ice water content itself appears to slightly decrease with SST (Del Genio and Kovari 2002).

Vertical velocity is correlated with thermodynamic parameters such as relative humidity and lapse rate that might control the development of convective storms (Del Genio and Kovari 2002). Thus, the fact that all hydrological and radiative properties examined in Fig. 1 are independent of $\omega$ suggests that these properties might be parameterized simply using purely thermodynamic and microphysical considerations. On the other hand, the absence of a relationship to $\omega$ may simply indicate large errors in this quantity on the 5-day time scale in ERA-40. In the next section we argue that there is in fact real information content in reanalysis $500-\mathrm{mb}$ $\omega$ on this time scale.

\section{Storm cloud areal coverage}

The upper panels of Fig. 2 show (left) the mean equivalent radius of TRMM storms, derived from individual storm raining areas, and (right) the number of storms, as a function of SST for the three vertical velocity categories. Together these determine the total raining area. Storm size increases with SST, and there is a suggestion that strong upwelling regions contain slightly larger storms than other areas. The number of storms, which controls the total raining area, increases sharply with SST above $27^{\circ} \mathrm{C}$, and especially in strong upwelling regions. Storm number also declines above $29^{\circ} \mathrm{C}$, even in strong upwelling, a behavior not seen in other parameters. It is possible that this is due to the small sampling at the higher temperatures, but it could also be evidence of a real suppression of all but the larger storms in unfavorable thermodynamic conditions, such as strong low-level inversions, efficient evaporation of rain in warm air, or rapid buoyancy reduction by entrainment.

The TRMM analysis pertains only to the optically thick surface precipitating portions of convective systems. However, the more extensive nonprecipitating cirrus anvils and thin cirrus formed also by convective detrainment are also important for cloud feedback and are in fact the subject of the adaptive iris hypothesis. Lindzen et al. (2001) argue that cirrus cloudiness will decrease with warming while deep convective cloud cover increases. It is therefore useful to ask whether cirrus clouds actually behave differently from their deep convective counterparts in the current climate. Cirrus are common throughout the Tropics, often with no direct connection to convective events (Comstock and Jakob 2004). Thus, rather than trying to identify specific contiguous cirrus areas with individual storms, we aggregate $\mathrm{Ci}, \mathrm{Cs}$, and DCC statistics for $2.5^{\circ} \times 2.5^{\circ}$ gridded areas in the ISCCP dataset as functions of SST and vertical velocity.

The lower panels of Fig. 2 show the SST dependence (left) of DCC and (right) of all high clouds $(\mathrm{Ci}+\mathrm{Cs}+$ DCC) in the different $\omega$ categories. In mean downwelling regions, DCC and high cloud amount are relatively insensitive to SST. In upwelling regions, DCC and high cloud cover exhibit some of the same characteristics as storm IWP, increasing sharply at $\sim 27^{\circ}-28^{\circ} \mathrm{C}$ and then less sharply or leveling off beyond that. Unlike rain, IWP, and radiative properties, though, both DCC and high cloud cover increase systematically in the transition from downwelling to upwelling for a given SST. Thus, the picture that emerges is that areal coverage of convective storms and associated clouds are the combined result of thermodynamic and dynamic effects, which primarily control storm frequency, while the properties of storms once initiated are controlled by temperature alone.

A more direct approach is to ask how the areal coverage of individual high cloud types depends on the 

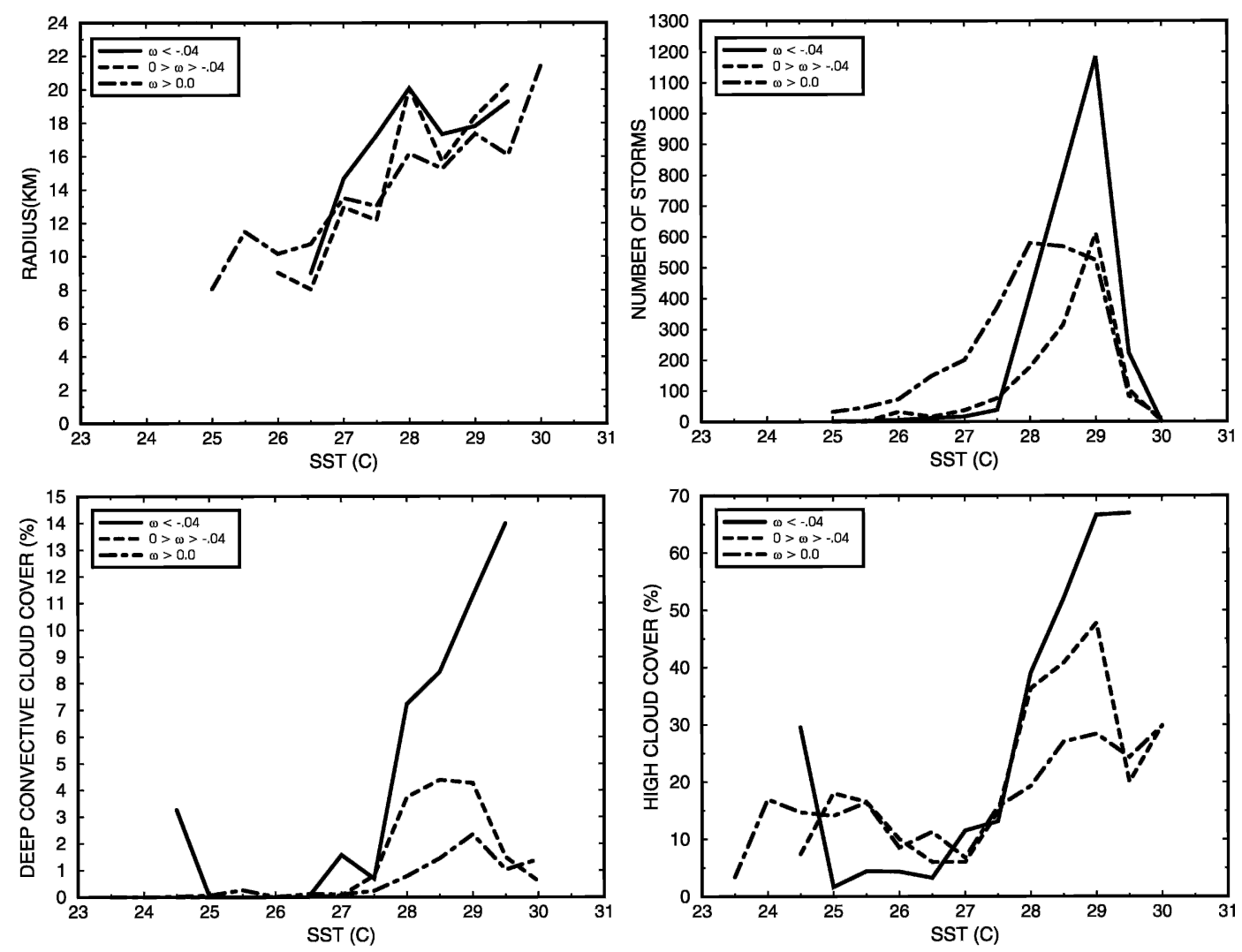

FIG. 2. As in Fig. 1 but for (top left) TMI storm equivalent radius, (top right) TMI number of storms, (bottom left) ISCCP deep convective cloud cover, and (bottom right) ISCCP high cloud cover.

amount of deep convection. Cirrus shields are often much larger than the $2.5^{\circ}$ latitude-longitude resolution of the ISCCP D1 products. Thus, a spurious negative correlation between instantaneous DCC and $\mathrm{Ci}$ amounts (correlation coefficient $r=-0.12$ ) and between DCC $+\mathrm{Cs}$ and $\mathrm{Ci}$ amounts $(r=-0.32)$ occurs at this resolution in the ISCCP data. In other words, since high cloud often fills the gridbox, more DCC + Cs area necessarily implies less $\mathrm{Ci}$ area. This artifact of gridding may partly explain the results of Lindzen et al. (2001), who use data at even finer $\left(1^{\circ}\right)$ resolution. We therefore aggregate the ISCCP data to $15^{\circ}$ resolution, which is large enough to ensure that the sum of the amounts of all high cloud types is almost always $<100 \%$. Figure 3 shows the relationship between the instantaneous DCC amount and the Cs (upper) and $\mathrm{Ci}$ (lower) cloud amounts in all $15^{\circ}$ boxes for the same spatial domain and time period used for the TRMM data analysis. The Cs amount is strongly positively correlated with DCC $(r$ $=0.79$, well above the $99 \%$ significance level for the sample size $N=694$ ). Also, the $\mathrm{Ci}$ amount is significantly positively correlated with DCC, but not as strongly $(r=0.36)$. The weaker correlation is due to a second population of $\mathrm{Ci}$ of varying cloud amount that exist in boxes with very small DCC amounts and may not be physically associated with convection. In fact about one-quarter of all cirrus clouds exist in $15^{\circ}$ areas that contain zero deep convective cloud. At the original $2.5^{\circ} \mathrm{D} 1$ resolution, about half of all cirrus lie in gridboxes with zero deep convection, consistent with the findings of Comstock and Jakob (2004) and Luo and Rossow (2004).

\section{Conceptual model of cumulus microphysics}

Most GCMs are poorly equipped to predict the microphysical properties and evolution of anvil clouds, because cumulus parameterization development has been overwhelmingly focused on closure and triggering assumptions, with convective water transport being an afterthought. Early cumulus parameterizations such as convective adjustment and Kuo schemes did not detrain convective condensate at all. This limits the possibility of thermostat-type behavior since convective cirrus cloud can only form indirectly from vertically mixed water vapor. Among schemes currently in use in climate GCMs, it is common to detrain a fixed fraction of the convective condensate (cf. Arakawa and Schu- 

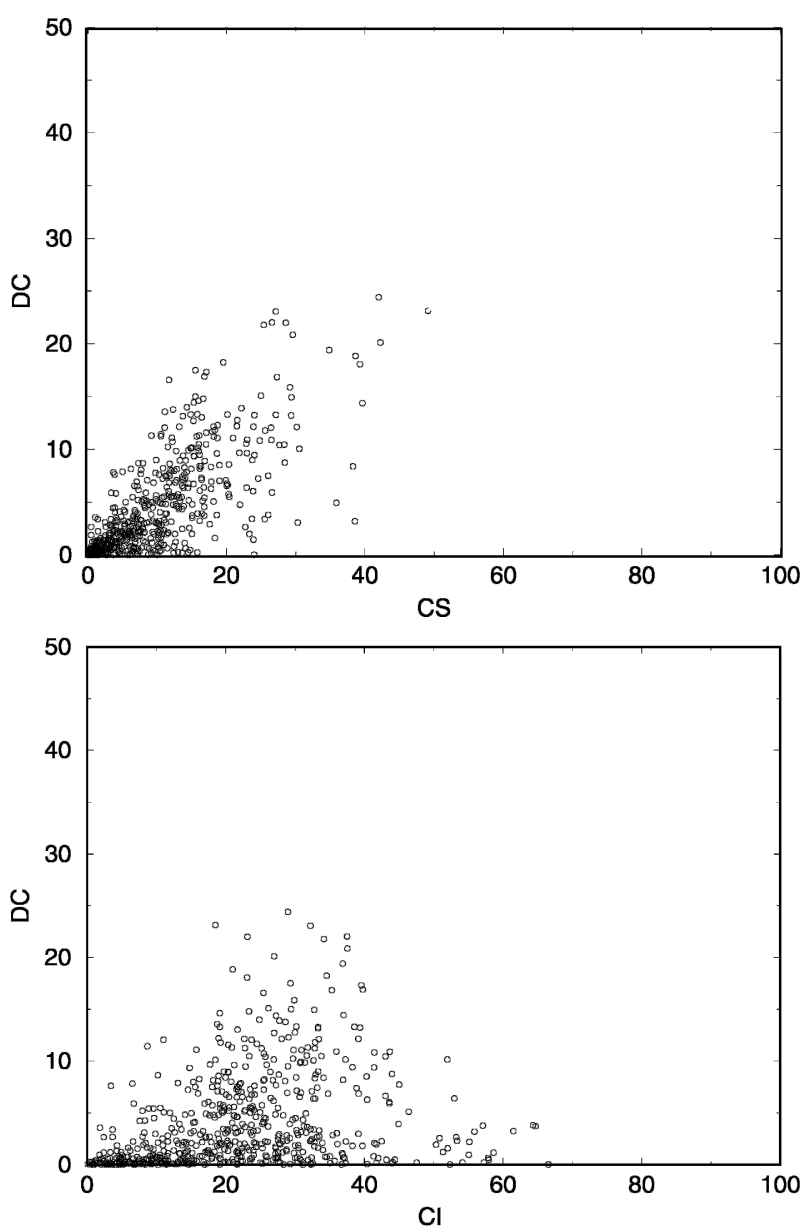

FIG. 3. ISCCP deep convective cloud amount vs (top) cirrostratus and (bottom) cirrus cloud amounts for the $15^{\circ} \mathrm{N}-15^{\circ} \mathrm{S}$ latitude band.

bert 1974; Tiedtke 1989; GFDL Global Atmospheric Model Development Team 2004). This ensures at least a moderate thermostat effect, since more convective condensate will form at warmer temperatures. The version of the GISS parameterization used for previous climate change studies (Del Genio and Yao 1993) converts all convective condensate to precipitation below the freezing level but detrains 50\% above the freezing level. Emanuel and Živković-Rothman (1999) assume a constant threshold cloud water content for conversion to precipitation below the freezing level and one that decreases to zero between the freezing level and $-55^{\circ} \mathrm{C}$; this approach would seem to slightly favor irislike behavior, since it does not allow convective condensate to detrain near the tropopause. The scheme of Sud and Walker (1999) is the only one to date to incorporate actual cumulus microphysics, using an assumed drop size distribution and computed updraft speeds to calculate precipitation formation and detrainment.
A simple conceptual model, similar in nature to the Sud and Walker approach, which allows for variable contributions to both detrainment and precipitation formation, is sufficient to qualitatively reproduce the satellite-observed behavior. We illustrate this using a two-layer atmosphere. The lower layer contains liquid convective condensate (density $\rho_{1}=1000 \mathrm{~kg} \mathrm{~m}^{-3}$ ) formed by lifting $80 \%$ relative humidity surface air to the freezing level, while the upper layer contains a cloud ice/snow (density $\rho_{\mathrm{i}}=100 \mathrm{~kg} \mathrm{~m}^{-3}$ ) + graupel (density $\rho_{\mathrm{g}}=400 \mathrm{~kg} \mathrm{~m}^{-3}$ ) mixture (differentiated by fall speed) formed by subsequent lifting from the freezing level to the convective cloud top temperature $T_{\mathrm{OLR}}$ implied by the mean CERES-observed OLR at different SSTs. For SST $<26^{\circ} \mathrm{C}$ the mean CERES convective cloud top is below the freezing level and thus we assume that only a liquid layer exists. The fraction of frozen condensate existing as ice/snow increases with decreasing $T_{\text {OLR }}$ as

$$
f_{i}=0.25\left[1-\exp \left(T_{\mathrm{OLR}} / 10\right)\right],
$$

with $T_{\mathrm{OLR}}$ in ${ }^{\circ} \mathrm{C}$. This is equivalent to assuming that frozen condensate is graupel-only at the freezing level, with increasing ice/snow fraction above.

We lift an air parcel from the bottom to the top of each layer and calculate the convective condensed water content as

$$
\begin{aligned}
& m=0.8 q_{s}(\mathrm{SST})-q_{s}\left(0^{\circ} \mathrm{C}\right) \text { (liquid layer), } \\
& m=q_{s}\left(0^{\circ} \mathrm{C}\right)-q_{s}\left(T_{\mathrm{OLR}}\right) \text { (ice layer), }
\end{aligned}
$$

where $q_{s}$ is the saturation specific humidity. We partition the condensate in each layer into a precipitating and a detrained part by making three assumptions:

1) Drop size distribution (DSD) for the droplet number concentration $N(D)$ at diameter $D$. The gamma distribution describes observed DSDs of individual convective cells quite well in a variety of situations. However, sufficient knowledge does not yet exist to allow the gamma distribution exponent to be predicted as a function of large-scale conditions. Furthermore, aggregated over an ensemble of convective cells in a large-scale area or over many different storms, the simpler Marshall-Palmer distribution

$$
N(D)=N_{o} \mathrm{e}^{-\lambda D},
$$

which corresponds to the gamma distribution with an exponent of 0 , is as or more representative of the mean DSD behavior than any other distribution shape (Ulbrich and Atlas 1998; Viltard et al. 2000) and is thus used in our model. In (3), $\lambda=\left(\pi \rho_{\mathrm{w}} N_{\mathrm{o}} /\right.$ $\mu)^{1 / 4}$, where $\rho_{\mathrm{w}}=\rho_{\mathrm{l}}$ (liquid), $\rho_{\mathrm{g}}$ (graupel), or $\rho_{\mathrm{i}}$ (ice), 
and $\mu=\mathrm{m} \rho$ (where $\rho$ is air density) is the adiabatic condensed water content in density units determined by (2). We take $N_{\mathrm{o}}=8 \times 10^{6} \mathrm{~m}^{-4}$, a typical value for storm systems (Marshall and Palmer 1948). This does not allow for the effect of variations in condensation nuclei, which may be nonnegligible in some cases.

2) Particle size-fall speed relationships for liquid, ice, and graupel. For liquid droplets, we use a fit to the terminal velocity measurements of Gunn and Kinzer (1949), adjusted for pressure variations with respect to surface pressure $p_{\mathrm{o}}$, given by Fowler et al. (1996) as

$$
\begin{aligned}
v_{\mathrm{tl}}(D)= & \left(-0.267+5.15 \times 10^{3} D-1.0225 \times 10^{6} D^{2}\right. \\
& \left.+7.55 \times 10^{7} D^{3}\right)\left(p_{\mathrm{o}} / p\right)^{0.4} .
\end{aligned}
$$

For $D=100 \mu \mathrm{m}$, about the smallest size drop that will precipitate in a convective cloud, this fit matches the data to an accuracy of $\sim 12 \%$; at $D=1$ $\mathrm{mm}$ the fit is accurate to $\sim 2 \%$. For graupel we use a pressure-adjusted version of the relationship for lump graupel derived from aircraft data by Locatelli and Hobbs (1974), given by

$$
v_{\mathrm{tg}}(D)=19.3 D^{0.37}\left(p_{\mathrm{o}} / p\right)^{0.4}
$$

and for ice/snow, a similar relation given by Rutledge and Hobbs (1984) as

$$
v_{\mathrm{ti}}(D)=1.139 D^{0.11}\left(p_{\mathrm{o}} / p\right)^{0.4} .
$$

3) Cumulus updraft speeds. Updraft velocities in convective clouds depend on the vertical profile of virtual temperature, entrainment rate, and cumulus scale vertical pressure gradients; the latter two are not easily parameterized in terms of GCM-resolved quantities. Since our purpose is to isolate the role of microphysics, we simply assume different values of the cumulus updraft speed $\mathrm{w}_{\mathrm{c}}$ that span the range of conditions commonly encountered in convective storms (cf. Lucas et al. 1994). For illustration purposes, we consider two different scenarios: (a) $w_{c}=$ $1 \mathrm{~m} \mathrm{~s}^{-1}$ throughout the cloud; (b) $w_{c}=5 \mathrm{~m} \mathrm{~s}^{-1}$ in the liquid and graupel portions of the cloud and 1 $\mathrm{m} \mathrm{s}^{-1}$ in the ice/snow portion. The latter scenario is intended to crudely mimic the effect of decreasing $w_{c}$ with height in the upper troposphere as parcels lose buoyancy as well as the fact that where graupel and ice coexist, the former usually exists preferentially in the stronger updraft regions.

Equations $(4 \mathrm{a}-\mathrm{c})$ are solved for the critical values of diameter $D_{c}$ at which $v_{t}=w_{c}$. The amount of convective condensate converted to precipitation is defined as the part of the mass distribution with $D>D_{c}$ :

$$
\begin{aligned}
\infty \mu_{p}= & \left(\pi \rho_{w} N_{\mathrm{o}} / 6\right) \int_{D_{c}}^{\infty} D^{3} \mathrm{e}^{-\lambda_{\mathrm{D}}} d D=\left(\pi \rho_{w} N_{\mathrm{o}} / 6\right) \mathrm{e}^{-\lambda D_{c}} \lambda^{-4} \\
& \times\left(D_{c}^{3} \lambda^{3}+3 D_{c}^{2} \lambda^{2}+6 D_{c} \lambda+6\right) .
\end{aligned}
$$

The remainder of the convective condensate in each layer is assumed to be detrained:

$$
\mu_{d}=\mu-\mu_{p} .
$$

Evaporation of rain and entrainment dilution is ignored in the simple conceptual model, but would be included if implemented in a GCM.

Figure 4 shows the partitioning between precipitation (left panels) and detrainment (right panels) as a function of SST. The upper panels show the behavior for a model with different fixed fractions of convective condensate detrained. The resulting systematic increase of detrained condensate with SST is clearly inconsistent with the observed asymptotic approach to an upper limit of detrained condensate (Fig. 1). The lower panels show the behavior of the cumulus microphysics model described above. Precipitation increases with SST monotonically and most sharply near and above $26^{\circ} \mathrm{C}$. The transition to rapidly increasing rainout is sharper for the weaker updraft speed because graupel $v_{t}>w_{c}$ for a significant fraction of the DSD in this case. The behavior of precipitation agrees qualitatively with the TRMM data shown in Fig. 1. The two cannot easily be compared quantitatively because the conceptual model is merely an estimate of the adiabatic condensed water content going into precipitation for a single updraft, while the observations represent the net precipitation reaching the ground in one hour in storms of varying updraft strength and lifetime after dilution by entrainment and evaporation. The more exaggerated SST dependence in the data is consistent with the idea of greater evaporation of rain and higher entrainment rates in shallower storms with smaller drops at colder SSTs.

Detrained water content in Fig. 4 (lower right) increases sharply with SST between $\sim 26^{\circ}$ and $28^{\circ} \mathrm{C}$ and then levels off at warmer values of SST. The detrainment curves bear a strong resemblance to the TRMM IWP observations, with the two vertical velocity choices bracketing the observed IWP values at high SST. The fact that detrainment neither increases indefinitely with SST (thermostat-type behavior), nor decreases systematically with SST (iris-type behavior) is the result of three simple pieces of physics. Figure 5, which shows the contributions to precipitation and detrainment for 

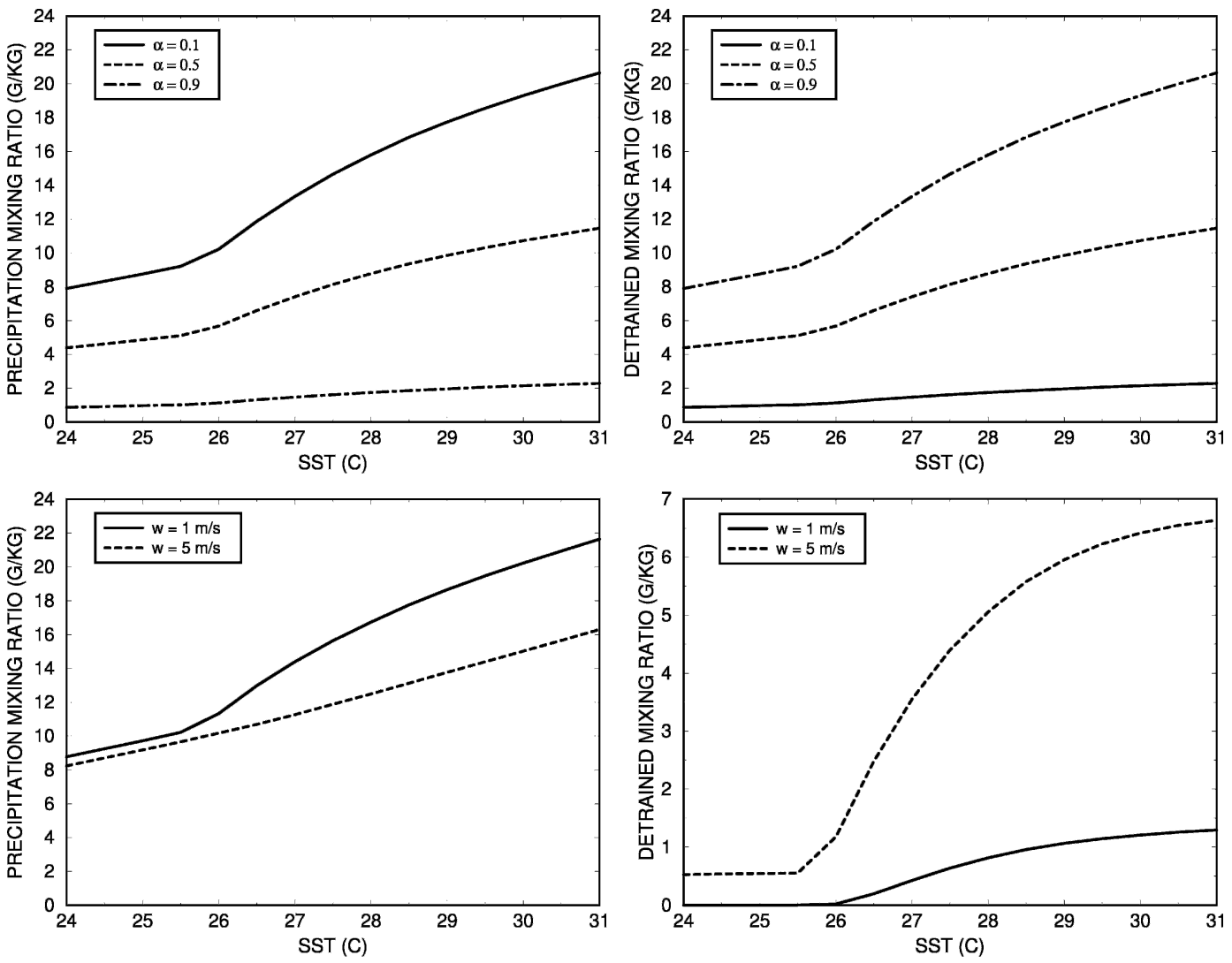

FIG. 4. (left) Precipitation and (right) detrained condensate mixing ratios for the two-layer conceptual model (top) under conditions of fixed fractional detrainment $\alpha=0.1,0.5$, and 0.9 and (bottom) for the interactive cumulus microphysics model with updraft speeds 1 and $5 \mathrm{~m} \mathrm{~s}^{-1}$.

liquid and ice + graupel separately, illustrates that 1$)$ precipitation formation efficiency is high and increases with warming below the freezing level (upper panel, solid curves), so although more vapor is available to condense at higher SST, the amount of condensate not rained out by the time the parcel reaches the freezing level is small and is only weakly sensitive to SST (upper panel, dashed curves); 2) The only effect of increasing SST and boundary layer humidity on ice formation is via increasing parcel buoyancy, causing increasing cloud-top height; frozen hydrometeors detrain more readily because of their lower terminal velocities relative to liquid drops (the transition from graupel to ice as top height increases has a similar effect);3) as cloud top reaches very high altitude at the warmest SSTs, cloudtop temperature becomes sufficiently cold that there is little additional ice mass to be formed by further increases in cloud top, according to the ClausiusClapeyron equation. Thus detrainment asymptotes to a maximum value. The relative amounts of precipitation and detrainment are sensitive to the choice of updraft speed, but the sense of the dependence on SST is not.

\section{Discussion}

Our results cast doubt on both the thermostat and adaptive iris hypotheses of convective regulation of climate change. Figure 2 suggests that much of the positive correlation between SWCF magnitude and SST reported by Ramanathan and Collins (1991) is due to the effect of varying vertical velocity on cloud cover rather than an intrinsic dependence on SST. The asymptotic behavior of IWP and high cloud cover at high SSTs suggests that there are limits to the extent that SW reflection can act as a thermostat to regulate SST. In fact other processes, such as convective downdrafts, may play an important role (Sud et al. 1999). TRMM rain rates confirm the tendency for increasing precipitation efficiency with warming that forms the basis for the adaptive iris hypothesis, but the failure of TRMM IWP and cirrus cloudiness to decrease with warming indicates that the physics highlighted by Lindzen et al. (2001) operates only near and below the freezing level, while upper level clouds and their radiative impact are determined mostly by parcel buoyancy and ice micro- 

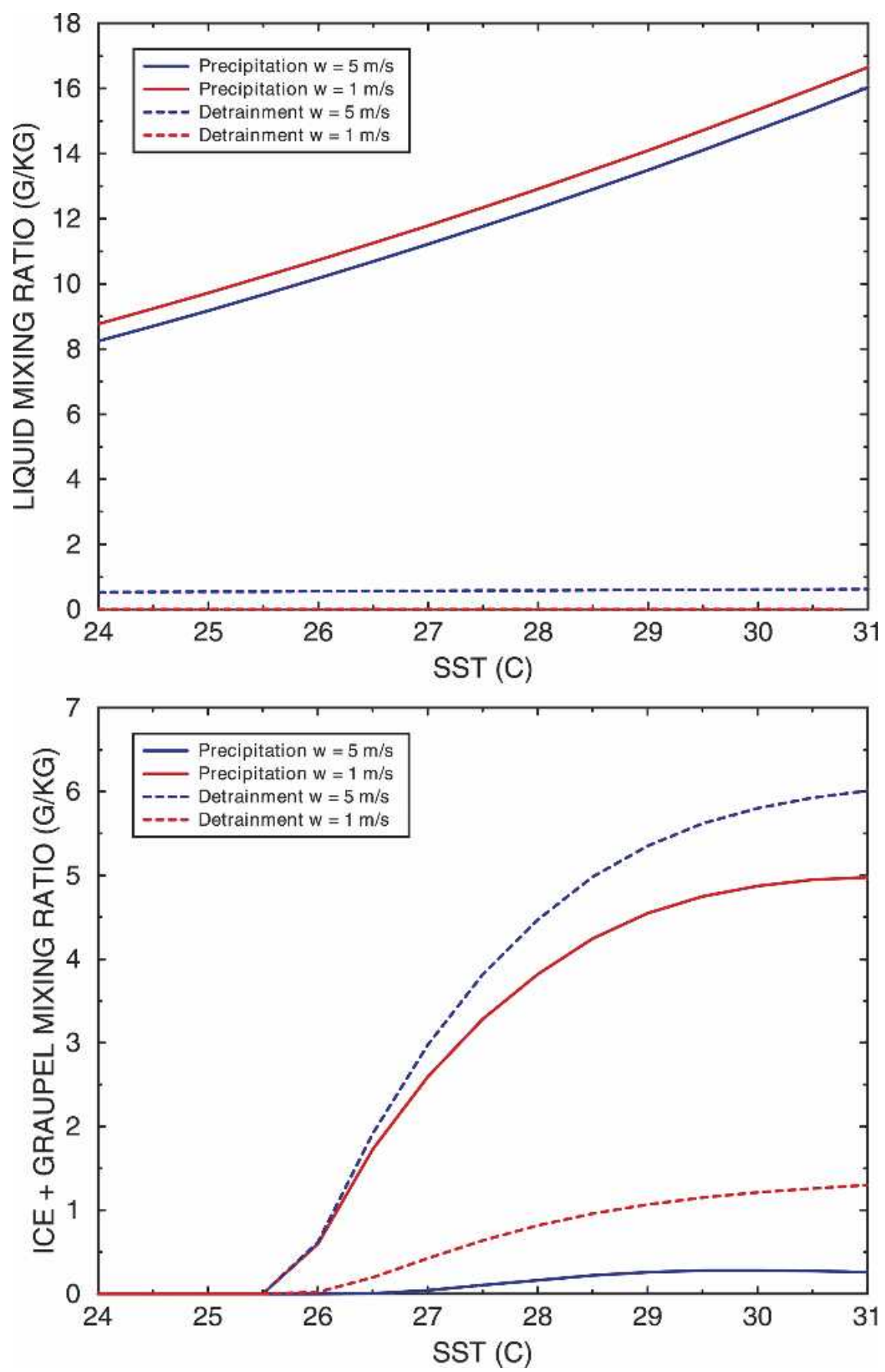

FIG. 5. (top) Liquid and (bottom) ice + graupel precipitation and detrainment mixing ratios vs SST for updraft speeds 1 and $5 \mathrm{~m} \mathrm{~s}^{-1}$ in the conceptual interactive cumulus microphysics model.

physics above the freezing level not taken into account in the iris picture.

We have shown that the behavior of actual convective storm and cirrus properties is unlike that needed to support either of the extreme theories. This might suggest that the real cloud feedback picture is somewhere in between, with ice formation at upper levels and con- densate removal at lower levels offsetting each other in regulating the top-of-atmosphere radiative balance. However, as mentioned earlier, it is difficult to infer the actual feedback from the data alone. We have adapted the physics in our conceptual model to the existing cumulus parameterization in the GISS Model E GCM, applying the model separately in each layer to partition 
precipitation and detrainment when deep convection occurs. Schmidt et al. (2005, manuscript submitted to $J$. Climate) provide a full description and an assessment of the resulting model's performance relative to observations and the previous version of the GISS GCM. Climate simulations with that model yield a climate sensitivity of $2.7^{\circ} \mathrm{C}$ to a doubling of $\mathrm{CO}_{2}$ and a nearly neutral cloud feedback, consistent with the observed current climate behavior of deep convective and cirrus clouds indicated by the TRMM and ISCCP data. This should not be taken as the final word on convective cloud feedback, since other cloud feedbacks are present in the global model. Furthermore, a single column model version of the GISS GCM exhibits somewhat larger temperature and moisture errors than do cloudresolving models (cf. Xie et al. 2002), and improving these aspects could change the cloud feedback. But it does illustrate that in at least one model, a microphysics scheme based on observations yields neither thermostat- nor iris-type cloud behavior.

Our results also have implications for water vapor feedback, which is actually the central point of the adaptive iris hypothesis. Figures 2 and 3 show that cirrus clouds are positively correlated with deep convection on relevant spatial scales and generally increase with SST, both of these the opposite of what is needed for the iris mechanism to operate. Thus, there is no reason to anticipate that increased precipitation efficiency in a warmer climate will lead to a drier atmosphere. The universally positive water vapor-lapse rate feedback in GCMs, which is insensitive to changes in cumulus parameterization, vertical resolution, or advective scheme (Del Genio et al. 1991; Ingram 2002) suggests that the feedback is regulated largely by changes in the large-scale dynamical transport of water vapor (Del Genio et al. 1994; Bauer et al. 2002). The fact that about half the cirrus detected by ISCCP in our analysis are apparently unrelated to convection supports the idea that vertical transport of water vapor in the tropical upper troposphere is not limited to convective clouds (cf. Comstock and Jakob 2004; Luo and Rossow 2004).

The physics discussed in this paper is only a first step toward the goal of realistic prediction of convective cloud feedback in GCMs. An obvious next step is a physically based parameterization of cumulus updraft speed. Several schemes have already been developed (Sud and Walker 1999; Donner et al. 2001; Gregory 2001), but a fundamental approach to the effects of entrainment and cumulus-scale pressure gradients does not yet exist. This would be a useful target for cloudresolving-model research.

In our conceptual model we differentiate only be- tween precipitation and detrainment in each layer. In reality only that part of the DSD with $v_{t} \sim w_{c}$ should detrain at a given level in a GCM, while the part with $v_{t}$ $\ll w_{c}$ is transported vertically with the updraft and detrains at some higher level. Given an interactive and realistic updraft speed profile, a droplet size binresolved assessment of precipitation, detrainment, and transport would be more appropriate.

Another useful step would be to generalize the DSD itself. In the context of the Marshall-Palmer DSD it would be more realistic to have a variable intercept $N_{\mathrm{o}}$, for example, as a function of temperature (Houze et al. 1979). Variable $N_{\mathrm{o}}$ would also allow for aerosol indirect effects on convective clouds such as those observed during a recent field experiment (Fridlind et al. 2004) to be represented in GCMs, which might modulate the precipitation-detrainment balance particularly for continental convection. Generalization of the DSD to a gamma function shape requires large-scale constraints on DSD variability under different environmental conditions. Such information might be available from the dual-frequency radar planned as the centerpiece of the Global Precipitation Mission. Extension of our conceptual model to the problem of drizzle in shallow convection is also possible, based on observed DSDs from field experiments. A fully self-consistent treatment would apply this approach to stratiform cloud precipitation as well, but this requires information not only on DSDs (cf. Heymsfield 2003) but also an accurate prediction of turbulence levels inside stratiform clouds, a difficult task for climate models.

Finally, the observational results presented in this paper suggest that convective and associated cirrus anvil cloud amount should be a primary focus of future parameterization research, given that these appear to depend on large-scale dynamical conditions as well as SST. To the extent that the observed vertical velocity dependence reflects the impact of relative humidity variations, existing schemes might simply be modified to better reproduce the observations. However, there is good reason to believe that dynamical factors not considered here, such as the vertical shear of the zonal and meridional wind, play a nonnegligible role in determining anvil evolution and cloudiness (Lin and Mapes 2004). These will be important to global climate sensitivity only if climate changes in the general circulation are greater than current GCMs predict, but shear may at least affect regional and temporal variability of convective cloud system radiative and hydrological properties.

The short-circuiting of thermostat effects in the liquid and (to some extent) warm ice portions of convective systems by increased precipitation efficiency at 
higher SST, and the simultaneous suppression of iris effects by the creation of more ice at higher convective cloud tops, depend on fundamental aspects of thermodynamics and microphysics that should be common to all physically plausible models. The degree to which climate changes in the upper and lower parts of anvils, and the resulting SW and LW feedbacks, compensate each other may vary somewhat depending on the details, but any GCM simulation in which the net contribution of convective clouds to climate sensitivity is far from neutral should be viewed cautiously unless it can reproduce the observational behavior presented here. We propose that the creation and application of similar observational metrics for other types of cloud objects would provide a useful path for reducing the remaining uncertainties in cloud feedback.

Acknowledgments. We thank Max Kelley for helpful discussions about this work and Lilly del Valle for assistance with the figures. This research was supported by the NASA CRYSTAL-FACE and Precipitation Measurement Missions Programs.

\section{REFERENCES}

Arakawa, A., and W. H. Schubert, 1974: The interactions of a cumulus cloud ensemble with the large-scale environment. Part I. J. Atmos. Sci., 31, 674-701.

Bauer, M., A. D. Del Genio, and J. Lanzante, 2002: Observed and simulated temperature-humidity relationships: Sensitivity to sampling and analysis. J. Climate, 15, 203-215.

Cess, R. D., and Coauthors, 1996: Cloud feedback in atmospheric general circulation models: An update. J. Geophys. Res., 101, 12 791-12 794.

Comstock, J. M., and C. Jakob, 2004: Evaluation of tropical cirrus cloud properties derived from ECMWF model output and ground based measurements over Nauru Island. Geophys. Res. Lett., 31, L10106, doi:10.1029/2004GL019539.

Del Genio, A. D., and M.-S. Yao, 1993: Efficient cumulus parameterization for long-term climate studies: The GISS scheme. The Representation of Cumulus Convection in Numerical Models, Meteor. Monogr., No. 46, Amer. Meteor. Soc., 181184.

—, and W. Kovari, 2002: Climatic properties of tropical precipitating convection under varying environmental conditions. $J$. Climate, 15, 2597-2615.

— - A. A. Lacis, and R. A. Ruedy, 1991: Simulations of the effect of a warmer climate on atmospheric humidity. Nature, 351, 382-385.

—-, W. Kovari, and M.-S. Yao, 1994: Climatic implications of the seasonal variation of upper troposphere water vapor. Geophys. Res. Lett., 21, 2701-2704.

Donner, L. J., C. J. Seman, and R. S. Hemler, 2001: A cumulus parameterization including mass fluxes, convective vertical velocities, and mesoscale effects: Thermodynamic and hydrological aspects in a general circulation model. J. Climate, 14, 3444-3463.

Emanuel, K. A., and M. Živković-Rothman, 1999: Development and evaluation of a convection scheme for use in climate models. J. Atmos. Sci., 56, 1766-1782.

Fowler, L. D., D. A. Randall, and S. A. Rutledge, 1996: Liquid and ice cloud microphysics in the CSU General Circulation Model. Part I: Model description and simulated microphysical processes. J. Climate, 9, 489-529.

Fridlind, A. M., and Coauthors, 2004: Evidence for the predominance of mid-tropospheric aerosols as subtropical anvil cloud nuclei. Science, 304, 718-722.

Fu, R., A. D. Del Genio, W. B. Rossow, and W. T. Liu, 1992: Cirrus cloud thermostat for tropical sea surface temperatures tested using satellite data. Nature, 358, 394-397.

GFDL Global Atmospheric Model Development Team, 2004: The new GFDL global atmosphere and land model AM2/ LM2: Evaluation with prescribed SST simulations. J. Climate, 17, 4641-4673.

Gregory, D., 2001: Estimation of entrainment rate in simple models of convective clouds. Quart. J. Roy. Meteor. Soc., 127, $53-72$.

Gunn, R., and G. D. Kinzer, 1949: The terminal velocity of fall for water droplets in stagnant air. J. Meteor., 6, 243-248.

Hartmann, D. L., and M. L. Michelsen, 2002: No evidence for iris. Bull. Amer. Meteor. Soc., 83, 1233-1238.

Heymsfield, A. J., 2003: Properties of tropical and midlatitude ice cloud particle ensembles. Part I: Median mass diameters and terminal velocities. J. Atmos. Sci., 60, 2573-2591.

Houze, R. A., Jr., P. V. Hobbs, P. H. Herzegh, and D. B. Parsons, 1979: Size distributions of precipitation particles in frontal clouds. J. Atmos. Sci., 36, 156-162.

Ingram, W. J., 2002: On the robustness of the water vapor feedback: GCM vertical resolution and formulation. J. Climate, 15, 917-921.

Kummerow, C., and Coauthors, 2001: The evolution of the Goddard profiling algorithm (GPROF) for rainfall estimation from passive microwave sensors. J. Appl. Meteor., 40, 18011820.

Lin, B., B. A. Wielicki, L. H. Chambers, Y. Hu, and K.-M. Xu, 2002: The iris hypothesis: A negative or positive cloud feedback? J. Climate, 15, 3-7.

Lin, J. L., and B. E. Mapes, 2004: Wind shear effects on cloudradiation feedback in the western Pacific warm pool. Geophys. Res. Lett., 31, L16118, doi:10.1029/2004GL020199.

Lindzen, R. S., M.-D. Chou, and A. Y. Hou, 2001: Does the earth have an adaptive infrared iris? Bull. Amer. Meteor. Soc., 82, 417-432.

Locatelli, J. D., and P. V. Hobbs, 1974: Fallspeeds and masses of solid precipitation particles. J. Geophys. Res., 79, 2185-2197.

Lucas, C., E. J. Zipser, and M. A. Lemone, 1994: Vertical velocity in oceanic convection off tropical Australia. J. Atmos. Sci., 51, 3183-3193.

Luo, Z., and W. B. Rossow, 2004: Characterizing tropical cirrus lifecycle, evolution, and interaction with upper-tropospheric water vapor using Lagrangian trajectory analysis of satellite observations. J. Climate, 17, 4541-4563.

Marshall, J. S., and W. McK. Palmer, 1948: The distribution of raindrop with size. J. Meteor., 5, 165-166.

Ramanathan, V., and W. Collins, 1991: Thermodynamic regulation of ocean warming by cirrus clouds deduced from observations of the 1987 El Niño. Nature, 351, 27-32.

Rayner, N. A., D. E. Parker, E. B. Horton, C. K. Folland, L. V. Alexander, D. P. Rowell, E. C. Kent, and A. Kaplan, 2003: Global analyses of sea surface temperature, sea ice, and night 
marine air temperature since the late nineteenth century. $J$. Geophys. Res., 108, 4407, doi:10.1029/2002JD002670.

Rossow, W. B., and R. A. Schiffer, 1999: Advances in understanding clouds from ISCCP. Bull. Amer. Meteor. Soc., 80, 22612288.

Rutledge, S. A., and P. V. Hobbs, 1984: The mesoscale and microscale structure and organization of clouds and precipitation in midlatitude cyclones. XII: A diagnostic modeling study of precipitation development in narrow cold-frontal rainbands. J. Atmos. Sci., 41, 2949-2972.

Simmons, A. J., and J. K. Gibson, 2000: The ERA-40 project plan. ERA-40 Project Report Series 1, European Centre for Medium-Range Weather Forecasting, Reading, United Kingdom, 63 pp.

Sud, Y. C., and G. K. Walker, 1999: Microphysics of clouds with the relaxed Arakawa-Schubert scheme (McRAS). Part I: Design and evaluation with GATE Phase III data. J. Atmos. Sci., 56, 3196-3220.

_ _ _ , and K.-M. Lau, 1999: Mechanisms regulating sea- surface temperatures and deep convection in the tropics. Geophys. Res. Lett., 26, 1019-1022.

Tiedtke, M., 1989: A comprehensive mass flux scheme for cumulus parameterization in large-scale models. Mon. Wea. Rev., 117, $1779-1800$

Ulbrich, C. W., and D. Atlas, 1998: Rainfall microphysics and radar properties: Analysis methods for drop size spectra. $J$. Appl. Meteor., 37, 912-923.

Viltard, N., C. Kummerow, W. S. Olson, and Y. Hong, 2000: Combined use of the radar and radiometer of TRMM to estimate the influence of drop size distribution on rain retrievals. $J$. Appl. Meteor., 39, 2103-2114.

Wielicki, B. A., B. R. Barkstrom, E. F. Harrison, R. B. Lee III, G. L. Smith, and J. E. Cooper, 1996: Clouds and the Earth's Radiant Energy System (CERES): An Earth Observing System experiment. Bull. Amer. Meteor. Soc., 77, 853-868.

Xie, S., and Coauthors, 2002: Intercomparison and evaluation of cumulus parameterizations under summertime midlatitude continental conditions. Quart. J. Roy. Meteor. Soc., 128, 1095-1136. 